UCRL-JC-126846

PREPRINT

\title{
The Edward Teller Medal Lecture: High Intensity Lasers and the Road to Ignition
}

\author{
M. H. Key
}

This paper was prepared for submittal to the Thirteenth International Conference on Laser Interactions and Related Plasma Phenomena

Monterey, California

April 13-18, 1997

June 2, 1997

This is a preprint of a paper intended for publication in a journal or proceedings. Since changes may be made before publication, this preprint is made available with the understanding that it will not be cited or reproduced without the permission of the author. 


\section{DISCLAIMER}

This document was prepared as an account of work sponsored by an agency of the United States Government. Neither the United States Government nor the University of California nor any of their employees, makes any warranty, express or implied, or assumes any legal liability or responsibility for the accuracy, completeness, or usefulness of any information, apparatus, product, or process

disclosed, or represents that its use would not infringe privately owned rights. Reference herein to any specific commercial product, process, or service by trade name, trademark, manufacturer, or otherwise, does not necessarily constitute or imply its endorsement, recommendation, or favoring by the United States Government or the University of California. The views and opinions of authors expressed herein do not necessarily state or reflect those of the United States Government or the University of California, and shall not be used for advertising or product endorsement purposes. 
UCRL-JC-126846

\title{
THE EDWARD TELLER MEDAL LECTURE: HIGH INTENSITY LASERS AND THE ROAD TO IGNITION
}

\author{
M. H. Key \\ Lawrence Livermore National Laboratory \\ Livermore, California 94551
}

\begin{abstract}
There has been much progress in the development of high intensity lasers and in the science of laser driven inertially confined fusion such that ignition is now a near term prospect. This lecture reviews the field with particular emphasis on areas of my own involvement.
\end{abstract}

\section{INTRODUCTION}

The development of high intensity lasers and the evolution of ideas and experiments for laser driven inertially confined fusion are twin themes with which my scientific interests have been entwined for three decades. During that time the concept of ignition of inertially confined fusion with lasers has evolved from early suggestions that kilojoule scale of laser energy might be sufficient to a mature and accurate understanding that a megajoule laser is required for central spark ignition in indirectly driven implosions (1).

When I worked from 1966 at Queens University Belfast and from 1976 to 1996 at a central facility for academic users of high power lasers which was established in 1976 at the Rutherford Appleton Laboratory (RAL), the scale of laser energy compatible with the level of resources in those academic programs was limited and at RAL we could not go beyond the few kilojoule range. In the mid 1980s however new ideas in laser physics opened up the possibility of ultra-high intensity lasers of moderate energy which we exploited vigorously at RAL from 1989 onwards. Outstanding work by colleagues Chris Edwards and Colin Danson and Mick Shaw and Graham Hirst respectively contributed to two significant new laser facilities at RAL. The first was the adaptation of a beam line of the multi beam Nd glass laser system Vulcan to operate with chirped pulse amplification (CPA) which boosted the individual beam power from 0.5 to $40 \mathrm{TW}$ (2). The second was development of very novel high intensity KrF CPA (3) and Raman (4) laser systems Sprite then Titania. With these lasers RAL scientists and facility user teams from UK universities and collaborators from overseas conducted some of the earliest experiments at more than $10{ }^{19} \mathrm{Wcm}^{-2}$.

My most recent task since joining the Lawrence Livermore National Laboratory (LLNL) in October 1996 is to guide experiments designed to evaluate the new concept of fast ignition. I am fortunate in working at LLNL with Max Tabak and 
colleagues who originated the fast ignition scheme (5) and to have access to a petawatt CPA beam at the Nova laser developed by Mike Perry and colleagues (6), which is by an order of magnitude the most powerful laser beam available today.

\section{FUSION PERSPECTIVE}

After two decades of evolution, ignition of inertially confined fusion (ICF) has become the near term goal of projects in the USA and France which are based on building megajoule laser facilities. There is a high level of confidence in achieving ignition with indirect drive and research into ignition by direct drive has reached a mature level with the new megajoule lasers configured to include direct drive as an option. Gain up to ten fold in fusion energy relative to laser energy is expected, as illustrated in Fig. 1 showing the indirect drive point design for the US National Ignition Facility (NIF). The relative status of progress in magnetic fusion energy research (MFE) and ICF has been changed significantly by these developments as is now expected that ICF ignition will be obtained before a self sustaining burn in MFE.

A limitation in the ICF work is that the expected gain in indirectly driven targets is too low for realization of an energy source by inertial fusion IFE (1). For a laser driver with typically less than $10 \%$ efficiency, gain in excess of 100 is required. Moreover even with further optimization, the isobaric central spark ignition used in both indirect and directly driven implosions has a limiting gain (7) for a realistic $8 \%$ hydrodynamic efficiency and compression adiabat ratio of 2 , which is less than 50 for circa $1 \mathrm{MJ}$ driver energy as illustrated in Fig. 1. Laser driven IFE does not therefore appear feasible at all with the isobaric scheme. An ion beam driver of higher efficiency is at present the only IFE option which could utilize the lower gain of implosions with the isobaric central spark.

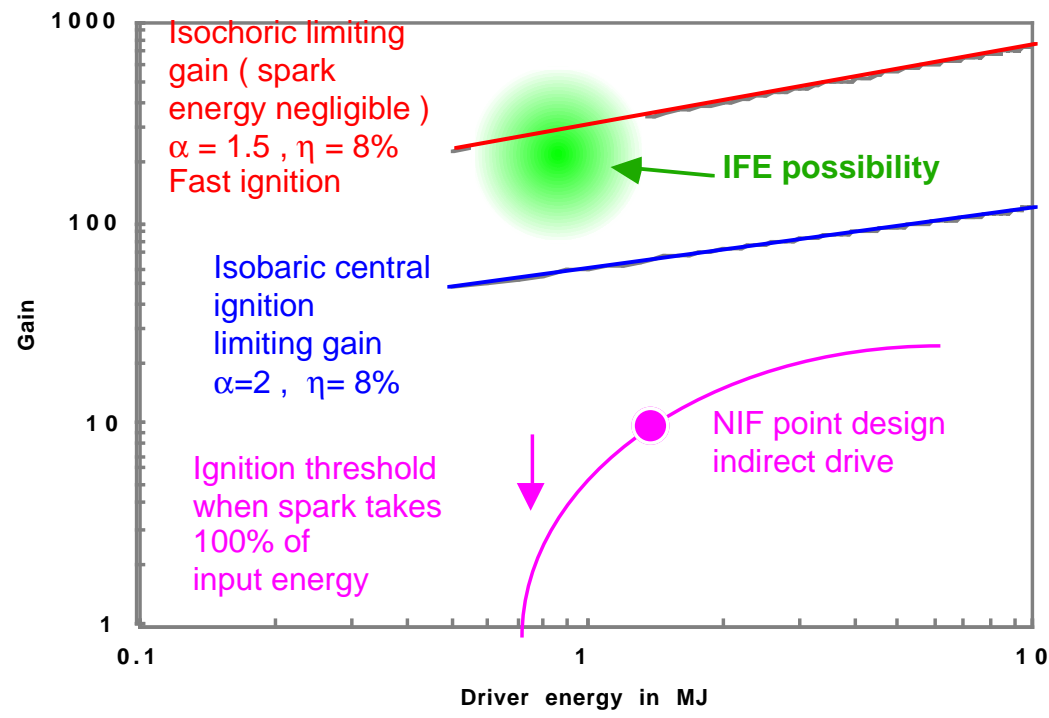

FIGURE 1.

With short pulse high intensity lasers came the new fast ignition scheme which is based irradiation in a single small focal spot of a pre-compressed target causing 
ignition under isochoric conditions for which the limiting gain exceeds 200 for 1 MJ driver energy. Although this new concept is relatively untested there is great interest in it as an alternative route to ignition because it opens up the possibility of IFE with lasers as a long term goal beyond the ignition facilities such as NIF.

\section{SOME MILESTONES}

The road to laser driven ICF ignition has been a long one on which some milestones can be identified. The first laser was demonstrated in 1960. The first laser initiated (but later understood to be non-thermonuclear) fusion reaction was reported in 1968 at the Lebedev Institute in the USSR. Much early research into the possibility of ICF was not in the public domain but in 1972 the principle of isobaric ignition in laser driven implosions was set our in a seminal publication by Nuckolls, Wood, Thiessen, and Zimmerman(8). Shortly after that in 1974 the KMS fusion Laboratory in the USA was the first to demonstrate thermonuclear fusion in a laser driven implosion (9). The use of indirect drive by thermal x-rays was pioneered behind a screen of classification at LLNL with early experiments from 1975 and continuous development up to the current NIF project. Declassification has recently opened up most of this area to wider involvement (1). Along the way a significant step was the discovery of laser plasma instabilities causing damaging preheating of the targets by energetic electrons leading to a vital change to the UV 3rd harmonic rather than the IR. fundamental frequency of the $\mathrm{Nd}$ glass laser for indirect drive . A major requirement in ICF is to achieve high density in order to reduce the critical mass and energy for ignition and in 1990 work at the Japanese Osaka University was the first to demonstrate a relevant density of $600 \mathrm{~g} / \mathrm{cc}$ in imploded polymer capsules using direct drive (10). Many other significant steps could also be identified from numerous laboratories world wide were this brief summary to be extended.

My personal milestones overlap in several ways with the road to laser driven ICF. My post graduate work at Imperial College in the early 1960's led me to build one of the first Q switched lasers and a theta pinch plasma in order to investigate the then new method of plasma diagnosis by Thomson scattering. As a post doctoral researcher in $1966 \mathrm{I}$ began to study plasmas produced by Q switched laser radiation. Moving in 1966 as a newly appointed faculty member to Queens University Belfast I built up a Nd glass laser facility which became the most powerful in the UK universities and used it to study x-ray emission from laser produced plasmas, to develop an x-ray streak camera and related diagnostic capabilities and to conduct early research into x-ray lasers. In 1976 when it was agreed to establish at the Rutherford Laboratory new Central Facility for UK university work with high power lasers, I moved there to coordinate the scientific work of the new project and in 1983 I became Head of the Facility. In the next decade at RAL we further developed the Nd glass laser named Vulcan and a $\mathrm{KrF}$ laser facility which we called Sprite. I worked also in collaboration with university 
colleagues on problems motivated by interest in fusion, developing $\mathrm{x}$-ray backlighting to study the dynamics of implosions (11) and hydrodynamic instabilities of laser accelerated targets (12). We also introduced new x-ray spectroscopy methods with streak time resolution (13) and space resolution for diagnostics such as preheat by hot electrons from K alpha fluorescence (14) and measurements of mass ablation rate (15). X-ray laser research became a substantial topic a highlight being demonstration of saturated $\mathrm{X}$-ray laser operation for the first time (16).

A significant reorientation of the RAL work began in 1989 with our decisions to emphasize high intensity physics by adapting Vulcan for CPA operation at up to 40 TW. 0.8 ps power and building a larger scale KrF laser Titania for both CPA and Raman laser operation. The KrF work is of a pioneering nature and the Raman system is particularly novel and unique. It offers near diffraction limited beams of up to $100 \mathrm{~J}$ energy and down to $20 \mathrm{ps}$ pulse length. In parallel with these developments I was invited to set up a university research group at Oxford University and with colleagues and students from Oxford studied topics in high intensity physics including optical field ionized plasmas (17), XUV high harmonics (18) and the application of x-ray lasers to measure laser imprinted hydrodynamic perturbations of importance in direct drive ICF (19).

\section{RECENT HIGH INTENSITY SCIENCE AT RAL}

The capability for experiments at up to $10^{19} \mathrm{Wcm}^{-2}$ at RAL has been important for the wider programs of facility users and much new science has been accomplished through and annual rate of up to 1000 high intensity shots over the last three years. Examples include measurements of relativistic self focusing (20) and high energy ion emission (21) and accelerated electrons (22).

Members of my Oxford University research group also contributed as users of the RAL lasers as the following examples illustrate . XUV high harmonic generation has interesting overlaps with x-ray laser research and offers some new possibilities for generating ultra-short pulses of high brightness. Two aspects here were of particular interest to us in connection with the Sprite/Titania laser facilities, which generate UV light unlike most of the lasers used for research into harmonic generation. The first was the possibility that harmonic conversion from ions rather than atoms would lead to shorter wavelength harmonics and the second was the anticipation from earlier work at wavelengths 1.05 and 0.53 micron, that a UV laser would give a higher conversion efficiency to harmonics of a given wavelength. In the event both these possibilities were successfully demonstrated, the first using the Sprite CPA laser leading to the shortest wavelength XUV harmonic with the 6.72 $\mathrm{nm} 37$ th harmonic of $248.6 \mathrm{~nm}$ from $\mathrm{He}^{+}$ions (18) and the second using the CPA beam of Titania with production of more than $10^{-6}$ conversion into the 7 th harmonic (23).

A most recent development was the pushing forward of the short wavelength limit 
at which saturated x-ray laser action has been observed using six beams of Vulcan operating with 70 ps pulse duration to irradiate a double slab target in two in line 100 micron wide line foci. The target material was $\mathrm{Sm}$ and the laser action on the $\mathrm{I} \cap 1$ line of the Nickel-like ionization stage was at $7.3 \mathrm{~nm}$ with a power of $6 \mathrm{MW}$ (Z4) illustrated in Fig. 2 .

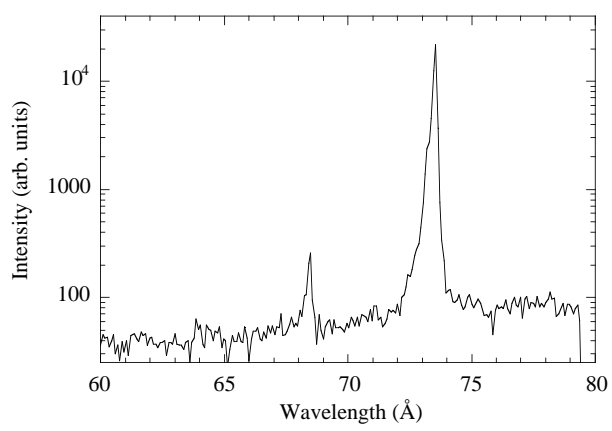

FIGURE 2. The spectrum of the Sm X-ray laser.

Continuing the theme of harmonics and short wavelengths the CPA beam of Vulcan was shown to produce an extended series of both odd and even harmonics when solid slab targets were irradiated at $10^{19} \mathrm{Wcm}^{-2}$ (25). The mechanism is the anharmonic motion of free electrons driven in and out across the critical density surface by the axial component of the electric field at the turning point of obliquely incident $\mathrm{p}$ polarized light. The novel feature of the results was that much shorter wavelength than in other experiments was observed down to the 75th harmonic of 1.05 micron and this was directly related to the high intensity. In an interesting follow up experiment the Doppler shift of the 4th harmonic was studied and it was shown that the extreme light pressure caused the critical density surface to recede at up to $1.5 \%$ of the velocity of light (26) as shown in Fig. 3, a process of interest for fast ignition which is discussed later, since it causes hole boring and steepening of the density profile.

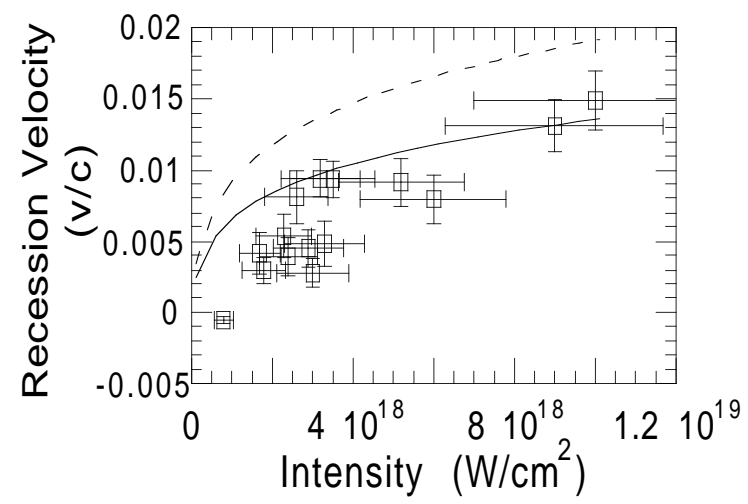

FIGURE 3. Recession velocity inferred from Doppler shifted 4th harmonic emission.

DIRECTLY DRIVEN ICF 
The majority of investment of research effort in ICF has gone into indirect drive but direct drive has remained of significant interest both because it is conceptually somewhat simpler and because its critical issues are different from indirect drive so that it provides a fall back option should unforeseen difficulties arise in indirect drive.

Perhaps the most critical issue in direct drive is the seeding of hydrodynamic instability in the implosion by the speckle pattern of the laser light driving the target. This imprinting process adds significantly to the initial perturbations of the spherical surface residual from its fabrication. The amplitudes of the perturbations is typically on the scale of a few tens of nanometers but the growth factors for Rayleigh Taylor instability are larger in direct than in indirect drive and the amplitude and frequency spectrum of the perturbations is a critical issue.

A natural extension of my interest in radiography and development of $\mathrm{x}$-ray lasers was to apply the $\mathrm{x}$-ray laser as a radiographic source to measure these small perturbations (19) as part of a broader effort to evaluate the direct drive fusion option which I embarked upon during a sabbatical year spent at LLNL in 1994/95.

The XUV laser offers high brightness and short pulse and together with normal incidence XUV optics, high spatial resolution in radiography. The high brightness enables measurements through targets with very large attenuation giving significant changes in transmission for small fractional changes in thickness.

This work began with colleagues at LLNL using the Nova laser (27) and was continued at the Vulcan facility which is better adapted for the purpose. Figure 4 illustrates $19.6 \mathrm{~nm}$ Ge laser radiographs of laser driven thin $\mathrm{Al}$ foils for three kinds of optical smoothing used in direct drive, the static speckle pattern of a random phase plate RPP, the one dimensionally fluctuating speckle of smoothing by spectral dispersion SSD and two dimensionally fluctuating speckle of induced spatial incoherence ISI (28). High quality data are obtained showing the thickness
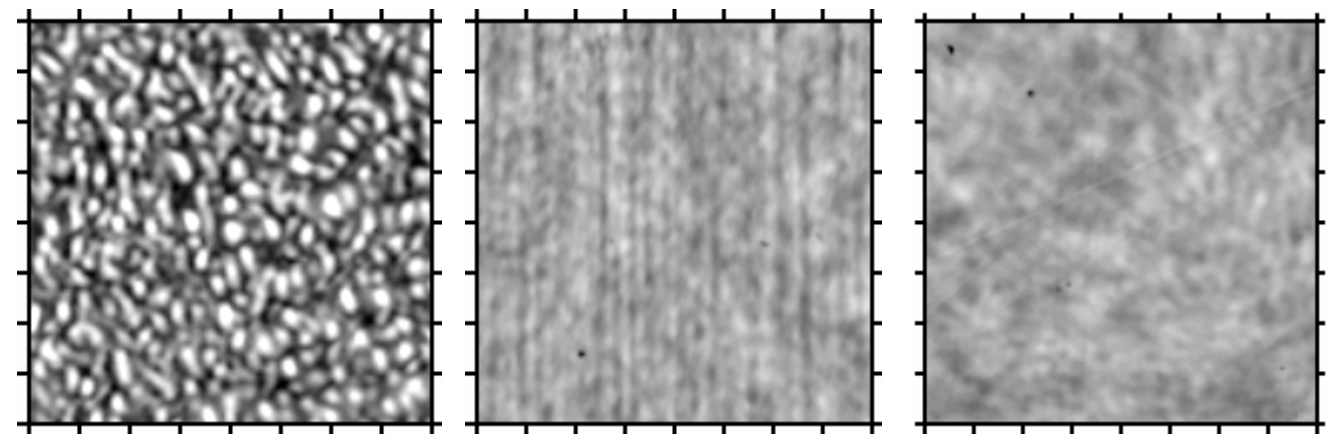

FIGURE 4. Radiographs showing 200 micron regions of 2 micron thick $\mathrm{Al}$ foil driven at $510^{12} \mathrm{Wcm}^{-2}$ recorded by XUV laser radiography for RPP. SSD and ISI smoothing respectively from left to right.

perturbations of the targets for amplitudes as low as $30 \mathrm{~nm}$. In related work a single optical mode (produced as a sinusoidal fringe pattern using a double slit aperture in the laser beam before the focusing lens) has been used to study a physically simpler system to allow more precise comparison with theory. 


\section{FAST IGNITION}

At LLNL there is a commitment to evaluate fast ignition both for its long term potential in IFE and for its nearer term interest as a possible adaptation of the NIF facility. The $1 \mathrm{~kJ}, 1 \mathrm{PW}$ beam line at Nova was built primarily for this task.

The relevant parameter range for the physics of fast ignition can be assessed from the fairly well established requirements of the ignition spark. Isochoric ignition needs some what higher temperature $(\mathrm{kT}=15 \mathrm{keV})$ and higher density radius product ( $\rho r=0.6 \mathrm{~g} / \mathrm{cc}$ ) than the $0.3 \mathrm{~g} / \mathrm{cm}^{2}, 5 \mathrm{keV}$ of isobaric ignition, because of the dissipation of energy in blast wave expansion of the spark. If $200 \mathrm{~g} / \mathrm{cc}$ is assumed for the compressed target the required radius is 30 micron and the thermal energy is $35 \mathrm{~kJ}$. If laser energy were converted to electrons and these were absorbed in the spark volume with a net $40 \%$ efficiency the laser energy would be $90 \mathrm{~kJ}$. Well collimated electrons and efficient absorption are required to achieve $40 \%$ net coupling. There will inevitably be some separation between the dense core and the laser absorption region which is estimated as of order one focal spot diameter and there must be some related increase in area from the laser focal spot to the heated spark which for plausibly well collimated electrons, is at least a factor of two. The pulse duration must be less than the inertial confinement time which is 30 ps in this example and if we therefore specify a 10 ps pulse, the necessary laser intensity is $610^{20} \mathrm{Wcm}^{-2}$.

The mean energy $\mathrm{E}$ of the electrons from PIC modeling is similar to the ponderomotive potential (5) which scales as $\left(\mathrm{I} \lambda^{2}\right)^{1 / 2}$ in the relativistic limit. For the example considered assuming 1 micron wavelength, $\mathrm{E}$ would be $6 \mathrm{MeV}$. This illustrates a problem in that we require the range of the electrons to match the $\rho$ r of the ignition spark. An energy of $1 \mathrm{MeV}$ is indicated unless collective behavior shortens the range. A solution here may be to use a shorter laser wavelength and in this example the required wavelength would be less than 0.2 micron.

A further interesting and often quoted possibility in fast ignition is to reduce the ignition energy by scaling up the density $\rho$. There is a $\rho^{-2}$ scaling of energy and a $\rho^{-}$ ${ }^{1}$ scaling of power with pulse length also scaling as $\rho^{-1}$. The apparent benefit is obvious but the required laser intensity scales as $\rho$ and exacerbates the problem of the electron energy.

A short wavelength is attractive also through reduction of the length of plasma with density above a few percent of critical because difficulties of channeling through the plasma increase with the length involved.

Experiments using the petawatt laser and detailed modeling are being carried out at 
LLNL to study and evaluate fast ignition. This work at a wavelength of 1.05 micron, is emphasizing the heating effect of the fast electrons and scaling behaviors. Results are preliminary and not yet published but early indications are encouraging and near keV temperature at near solid density has been inferred from $\mathrm{x}$-ray spectroscopy and DD fusion yield from buried layers in plane targets.

It is also apparent that while fast ignition requires short pulses it does not require ultra-short pulses and CPA lasers are not then so advantageous. The KrF Raman laser can generate a near diffraction limited beam at $268 \mathrm{~nm}$ in pulses as short as 30 ps and its intensity limit in the beam is about $30 \mathrm{GW} / \mathrm{cm}^{2}$ or $0.9 \mathrm{~J} \mathrm{~cm}^{-2}$. A CPA laser with metallic gratings is limited to $0.2 \mathrm{~J} / \mathrm{cm}^{2}$ and with dielectric gratings and pulses up to $30 \mathrm{ps}$ this figure may be increased to about $1 \mathrm{Jcm}^{-2}$. The two technologies therefore appear to have similar capabilities of energy delivery per area of beam.

It is much too early to draw any conclusions on the viability of fast ignition and on the required wavelength but it would be an interesting closure of loops were I to find as a result of my move to LLNL that fast ignition needs the $\mathrm{KrF}$ laser technology which we pioneered at RAL!

\section{ACKNOWLEDGMENTS}

I am grateful to many colleagues at RAL, Oxford University, other UK universities, LLNL and in other laboratories outside the UK for their contributions to the research and development activities reviewed here. Experimental science is in essence team work and I have been fortunate in the quality of the team members with whom I have worked.

Work performed under the auspices of the U.S. Department of Energy by the Lawrence Livermore National Laboratory under Contract No. W-7405-ENG-48.

\section{REFERENCES}

1. Lindl, J. D., "The evolution towards indirect drive and two decades of progress towards ICF ignition and burn," Laser Interaction and Related Plasma Phenomena, AIP Conf. Proc. 318 , p. 635, (1993).

2. Danson, C. N., Barzanti, L., Chang, Z., Damerell, A., Edwards, C. B., Hancock, S., Hutchinson, M. H. R., Key, M. H., Luan, S., Mahadeo, R., Mercer, I. P., Norreys, P., Pepler, D. A., Rodkiss, D. A., Ross, I. N., Smith, M. A., Smith, R. A., Taday, P. F., Toner, W. T., Wigmore, K., Winstone, T. B., Wyatt, R. W., "High contrast multi-terawatt pulse generation using chirped pulse amplification on the VULCAN laser facility," Opt. Comm., 103, 392, (1993).

3. Ross, I. N., Damerell, A. R., Dival, E. J., Evans, J., Hirst, G. J., Hooker, C. J., Key, M. H., Lister, J. M. D., Osvay, K., M. J. Shaw, "A 1 TW KrF laser using chirped pulse amplification," Opt. Comm., 109, 288 (1994). 
4. Ross, I. N., Shaw, M. J., Hooker, C. J., Key, M. H., Harvey, E. C., Lister, J. M. D., Andrews, J. E., Hirst, G. J., Rogers, P. A., "A high performance excimer pumped Raman laser," Opt. Comm., 78, 262, (1990).

5. Tabak, M., Hammer, J., Glinsky, M. E., Kruer, W. L., Wilks, S. C., Woodworth, J., Campbell, E. M., Perry, M. D., "Ignition and high gain with ultra-powerful lasers," Phys. Plasmas 1, 1626 (1994).

6. Perry, M. D., and Morou, G., "Terawatt to petawatt subpiocosecond lasers," Science 264, 917, (1994).

7. Atzeni, S., "Thermonuclear burn performance of volume ignited and centrally ignited bare deuterium tritium microspheres," Jpn J. Appl. Phys. 34, 1980 (1995).

8. Nuckolls, J., Wood, L., Thiessen, A., Zimmerman, G., "Laser compression of matter to superhigh densities: thermonuclear (CTR) applications," Nature 239, 139 (1972).

9. Campbell, P. M., Charatis, G. G., Montry, R., "Laser driven compression of glass microspheres Phys. Rev. Lett. 34, 74, (1975).

10. Azechi, H., Jitsuno, T., Kanabe, T., Katayama, M., Mima, K., Miyanaga, M., Nakai, M., Nakai, S., Nakaishi, H., Nakatsuka, M., Nishiguchi, A., Norreys, P. A., Setsuhara, Y., Takagi, M., Yamanaka, M., Yamanaka, C., "High-density compression experiments at ILE, Osaka," Lasers and Particle Beams 9, 193, (1991).

11. Key, M. H., Lewis, C. L. S., Lunney, J. G., Moore, A., Hall, T. A., Evans, R. G., "Pulsed x-ray shadowgraphy of dense cool laser imploded plasma," Phys. Rev. Letts. 41, 1467 (1978).

12. Rumsby, P. T., Key, M. H., Hooker, C. J., Cole, A. J., Kilkenny, J. D., Evans, R. G., "Measurement of Rayleigh-Taylor instability in a laser accelerated target," Nature 299, 329 (1982).

13. Key, M. H., Lewis, C. L. S., Lunney, J. G., Moore, A., Ward, J. M., Thareja, R.K., "Time resolved x-ray spectroscopy of laser produced plasmas," Phys. Rev. Lett. 44, 1669 (1980).

14. Hares, J. D., Kilkenny, J. D., Key, M. H., Lunney, J. G.,"Measurement of fast electron energy spectra and preheating in laser irradiated targets," Phys. Rev. Letts. 42, 1216 (1979).

15. Key, M. H., Toner, W. T., Goldsack,, T. J., Veats, S. A., Kilkenny, J. D., Cunningham, B. J., Lewis, C. L. S., "A study of laser ablation by laser irradiation of plane targets at wavelengths 1.06, 0.53 and 0.35 micron," Phys. Fluids 26, 7, 2011 (1983).

16. Carillon, A., Chen, H. Z., Dhez, P., Dwivedi, L., Jaegle, P., Jamelot, G., Zhang, J., Key, M. H., Kidd, A., Klisnick, A., Kodama, R., Krishnan, J., Lewis, C. L. S., Neely, D., Norreys, P., Oneill, D. M., Pert, G. J., Ramsden, S. A., Raucourt, J. P., Tallents, G. J., Uhomoibhi, J., "Saturated and near diffraction limited operation of an XUV laser at $23.6 \mathrm{~nm}$," Phys. Rev. Lett., 68, 2917, (1992).

17. Blyth, W. J., Preston, S. G., Offenberger, A. A., Key, M. H., Wark, J. S., Najmudin, Z., Modena, A., Djaoui, A., Dangor, A. E., "Plasma temperature in optical field ionisation of gases by intense ultra-short pulses of ultraviolet radiation," Phys. Rev. Lett. 74, 554, (1995).

18. Preston, S. G., Sanpera, A., Zepf, V., Blyth, W. J., Smith, C. G., Burnett, K., M. H., Key, Wark, J. S., Neely, D., Offenberger, A. A., "High order harmonics of $248.6 \mathrm{~nm} \mathrm{KrF}$ laser from helium and neon ions," Phys. Rev. A, 53, R31, (1996).

19. Key, M. H., Barbee Jr., T. W., DaSilva, L. B., Glendinning, S. G., Kalantar, D. H., Rose, S. J., Weber, S. V., "New plasma diagnostic possibilities from radiography with XUV lasers," J Quant . Spectr. and Radiative Transfer, 54, 221, (1995).

20. Borghesi, M., MacKinnon, A. J., Baringer, L., Gaillard, R., Gizzi, L. A., Meyer, C., Willi, O., Pukhov, A., Meyer ter Vehn, J., "Relativistic channelling of a picosecond laser pulse in a near critical preformed plasma," Phys. Rev. Letts. 78, 879 (1997).

21. Fews, A. P., Norreys, P. A., Beg, F. N., Bell, A. R., Dangor, A. E., Danson, C. N., Lee, P., Rose, S. J., "Plasma ion emission from high intensity picosecond laser pulse interactioins with solid targets," Phys. Rev. Letts. 73, 1801 (1994). 
22. Modena, A., Najmudin, Z., Dangor, A. E., Clayton, C. E., Marsch, K. A., Joshi, C., "Electron acceleration from the breaking of relativistic plasma waves," Nature 377, 606 (1995).

23. Preston, S. G., Chambers, D. M., Marjoribanks, R. S., Norreys, P. A., Neely, Zepf, M., Zhang, J., Key, M. H., Wark, J. S., "A krypton fluoride laser source of bright, extremeultraviolet harmonic radiation," Phys. Rev. A (submitted).

24. Zhang, J., McPhee, A. G., Lin, J., Wolfrum, E., Smith, R., Danson, C., Key, M. H., Lewis, C. L .S., Neely, D., Nilsen, J., Pert, G. J., Tallents, G. J., Wark, J. S., "A saturated X-ray laser beam at $7 \mathrm{~nm}$," Science 276, 1097 (1997).

25. Norreys, P. A., Zepf, M., Moustaizis, S., Fews, A. P., Zhang, J., Lee, P., Bakarezos, M., Danson, C. N., Dyson, A., Gibbon, P., Loukakos, P., Neely, D., Walsh, F. N., Wark, J. S., Dangor, A. E., "Efficient extreme UV harmonics generated from picosecond laser pulse interactionswith solid targets," Phys. Rev. Lett. 76, 1832 (1996).

26. Zepf, M., Castro-Colin, M., Chambers, D., Dangor, A. E., Danson, C. N., Dyson, A., Fews, A. P., Gibbon, P., Key, M. H., Lee, P., Moustaizis, S., Neely, D., Norreys, P. A., Preston, S. G., Wark, J. S., Zhang, J., "Measurement of the hole boring velocity from Doppler shifted harmonic emmission from solid targets," Phys. Plasmas, 3, 3242, (1997).

27. Kalantar, D. H., Key, M. H., DaSilva, L. B., Glendinning, S. G., Knauer, J. P., Remington, B. A., Weber, F., Weber, S. V., "Measurements of 0.35 micron laser imprint in a driven Si foil by XUV laser radiography," Phys. Rev. Letts. 76, 3574, (1996).

28. Kalantar, D. H., Da Silva, L. B., Demir, A., Glendinning, S. G., Key, M. H., Kim, N, S., Knauer, J. P., Lewis, C. L .S., Lin, J, Neely, D., MacPhee, A., Remington, B. A., Smith, R., Tallents, G. J., Wark, J. S., Warwick, J., F. Weber, Weber, S. V., Wolfrum, E., Zhang, J., "XUV probing of laser imprint in a thin foil using an x-ray laser backlighter," Rev .Sci. Instr. 68, 802 (1997). 


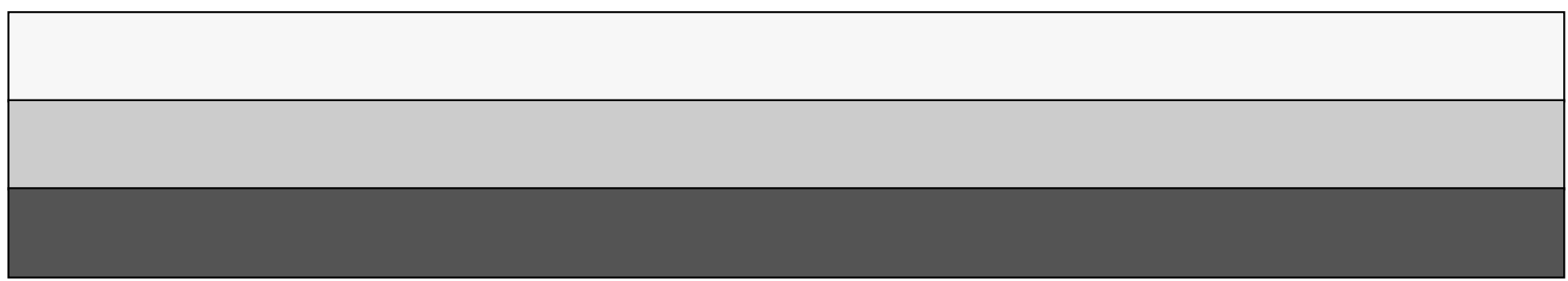

